\title{
Advanced Mathematics Teaching Reform Research Based on the Perspective of Traditional Chinese Medicine Application
}

\author{
Chunlan Mou* \\ School of Administration \\ Shandong Traditional Chinese Medicine University \\ Jinan, China \\ zuiaidul@163.com \\ (*Corresponding author)
}

\begin{abstract}
With the rapid development of information technology, Chinese medicine research has gradually changed from qualitative to quantitative research. In this process, mathematics has shown an increasingly important position. It is of vital importance to train students of traditional Chinese medicine colleges to use mathematical thinking to understand, analyze and solve problems related to Chinese medicine. This paper studies how to carry out teaching reform in advanced mathematics colleges and universities from the perspective of traditional Chinese medicine application. Firstly, Reasonable positioning of the application value of advanced mathematics in the field of traditional Chinese medicine. This value orientation should be combined with the goal of talents training in traditional Chinese medicine colleges; Secondly, carrying out classroom teaching reform, building a new talent training model; Finally, applying the research results.
\end{abstract}

Keywords-advanced mathematics; traditional Chinese medicine; teaching reform; value orientation; talent training mode

\section{INTRODUCTION}

With the advent of the information age, information technology has developed rapidly, and Chinese medicine research has gradually changed from qualitative research to quantitative research. In this process, mathematics has shown an increasingly important position and has been integrated with many disciplines to form marginal disciplines (such as Pharmacokinetics), so it is very important to increase the mathematics knowledge of students in Chinese medicine colleges and to develop their ability to use mathematics to understand, analyze and solve problems in the field of Chinese medicine. However, the current status quo is that many Chinese medicine majors in Chinese medicine colleges have not yet offered advanced mathematics courses. Most Chinese medicine majors are offered, but students generally lack interest in mathematics, thinking mathematics is useless, and it is existing only for exams. The really reason is that students have not realized the importance of mathematics in the field of Chinese medicine.

According to the 1983 UNESCO report, "One of the characteristics of current scientific research is the mathematics of science. It has become a historical trend in scientific development." The wave of digitization is moving toward biomedicine, biomedicine has also provided countless research topics to mathematics. The Swiss mathematician Jeme pioneered a new model of modern medical research in his paper "Immunological Network Structure Theory", which won the 1985 Medical Nobel Prize.

Although a fairly high level of mathematics has begun to appear in the biomedical field, there is still a big gap between mathematics and biomedicine. Among them, traditional Chinese medicine is the most important. Many experts of Chinese medicine circle pointed out that a very important reason for the slow development of Chinese medicine is that it has never taken the stage of mathematics, and has not inserted the "mathematical wings". Because there is no mathematics, many concepts have become unclear, and even with the teacher's many clinical practices, it is difficult to understand one or two. The development of traditional Chinese medicine is still in the stage of empirical science, that is, as the saying goes: "The older Chinese medicine is more fragrant."

Consulting many literatures, many experts and scholars have explained that mathematics is the foundation of the natural science foundation. It is widely infiltrated into the medical science field, but how should it penetrate, how to penetrate quickly, there is few people has studied. Many teachers are trying to reform teaching methods. but why to reform, how to guide students is very vague, they have no clear goal. This article is based on the field of traditional Chinese medicine, positioning the application value of advanced mathematics in the field of traditional Chinese medicine, and combining this orientation with the training objectives of Chinese medicine colleges, then sharing it with teachers and students, and cultivating and guiding students' mathematical thinking. At the same time carrying out corresponding teaching reforms, and constructing a new talent training model with Chinese medicine characteristics, this will undoubtedly have great theoretical and practical value for accelerating the quantitative and scientific development of Chinese medicine, and helping to realize the modernization of Chinese medicine. 


\section{LITERATURE REVIEW}

The idea of applying mathematics to the field of medicine is not new. Many scholars have proposed and completed some research results, but the application of mathematics in the field of traditional Chinese medicine is relatively scarce. In fact, many scholars have realized that mathematics has " a lot of work" in the field of traditional Chinese medicine, but it is difficult to change students' concepts of 'higher mathematics uselessness" and "mathematics and Chinese medicine does not touch the edge", which seriously affects the quantitative research of traditional Chinese medicine, and hinders the scientific development and the realization of modernization of traditional Chinese medicine.

Current medical education researchers have conducted active discussions on these phenomena and problems. Cui Hongxin and Zhao Wenfeng (2005) believe that with the development of biomathematics, mathematics must infiltrate into the medical science. The essence of mutual penetration of medicine and mathematics is to enable qualitative research in medical science to quantitatively study and propose to improve students' medicine advanced mathematics interest should focus on the theory and practice, and use mathematical knowledge to solve practical problems in medicine. Bian Li (2009) believes that the existing advanced mathematics textbooks are out of touch with the actual medical applications. The traditional teaching model cannot guide students to combine mathematics and the application of traditional Chinese medicine. The learning atmosphere that students and teachers are alienated is the main reason why it is difficult to achieve higher mathematics in the field of traditional Chinese medicine.. She proposed to adjust the curriculum requirements, reform the teaching materials; improve the knowledge of teachers in Chinese medicine; establish a harmonious teacher-student relationship and other strategies. Gu Licui (2012) believes that the past teaching of advanced mathematics in medical colleges pays too much attention to the completeness and rigor of the theory. So in the case of limited academic hours, there is no enough time to explain how to solve practical problems mathematically which leads to students feel that mathematics is useless and it is just to learn mathematics for the exam. At the same time, it is difficult for students to link the theoretical methods of mathematics with the actual medical problems, and they can't apply what they have learned, which has caused the disjointed phenomenon of "learning" and "using". She proposed to introduce the discussion-based teaching method to achieve the teaching goal of "application-oriented, sufficient use" in higher mathematics. Through discussion, inspire students to express their own opinions on specific issues, quantitatively analyze and solve medical problems with advanced mathematics knowledge. And deeply understand the applicability of higher mathematics in the field of medicine, and cultivate students' independent thinking ability, application ability and innovative spirit. Zhang Congqiong and Huang Jian (2000) pointed out that as teachers of medical colleges; they have the responsibility and obligation to contribute to the mathematical process of medicine.

Prior to this, the results of a few researchers who applied mathematics to traditional Chinese medicine were very significant. For example, Professor Zhang Qiming, an influential professor at Shandong University of Traditional Chinese Medicine, applied non-thermodynamics to the basic theory of Chinese medicine in 1990. It reveals that the cause of sympathetic yin and yang is the result of the body inputting negative entropy from the outside world by means of metabolism. In 1995, he established the first mathematical model of non-linear macromolecular equations for the changes of the five internal organs of Chinese medicine. The discovery of the "five-soil singular attractors" attracted the interest of European and American experts at the Third International Symposium on Systems Science and Systems Theory. However, the application of mathematical science in the field of traditional Chinese medicine is still far from playing its due role. Therefore, Chinese medicine should be inserted into the "mathematical wings" as soon as possible to realize the transformation from qualitative research to quantitative research, in order to obtain the acceleration mechanism of the development of traditional Chinese medicine, which is also a fast and effective way to realize the modernization of traditional Chinese medicine.

\section{THE APPLICATION VALUE POSITIONING OF ADVANCED MATHEMATICS IN THE FIELD OF TRADITIONAL CHINESE MEDICINE}

The application of advanced mathematics in the field of traditional Chinese medicine will promote the research of traditional Chinese medicine from empirical science to experimental science. It is a tool, means and method for carrying out research on related issues in the field of traditional Chinese medicine. It is necessary for students to have a good grasp of the tools for studying Chinese medicine related issues. First of all, teachers need to be experts in the field of mathematics, and also very familiar with the relevant issues in the field of traditional Chinese medicine, and the two can be combined in depth to better position them.

The value positioning of advanced mathematics in the field of traditional Chinese medicine application is mainly carried out from two aspects: First, the analysis of relevant literature, by analyzing relevant scholars and practitioners at home and abroad using advanced mathematics theory to analyze and study the related problems of traditional Chinese medicine, this article obtains the application and influence of mathematical methods and mathematical modeling on the internal laws of traditional Chinese medicine, research on traditional Chinese medicine and standardization of traditional Chinese medicine, and then analyzes its application value. Second, investigating the students who have advanced mathematics courses in the institute's college. At the end of mathematics course, students are required to use the term papers (the papers consist of several major modules, including: understanding of advanced mathematics, learning gains, application experience, ability improvement, etc.) to provide feedback on the experience of learning, which is used to analysis the current status of learning and application and provide a reference for the application of value orientation and the improvement of the next teaching model.

Starting from the goal of talent training, each discipline develops specific training objectives under the guidance of overall training requirements, generally from the three levels of 
knowledge, ability and quality. Therefore, the value orientation of the above advanced mathematics should be deeply integrated with the training objectives, by positioning the value to the specific training objectives; we can realize its value orientation in the process of talent cultivation. According to the three levels of specific objectives of TCM personnel training, the application value of advanced mathematics in the field of traditional Chinese medicine is also divided into three levels: one is the general target layer, which is to cultivate students' abstract thinking , logical reasoning ability and the necessary mathematical knowledge through the study of advanced mathematics; The second is the application target layer, training students to use advanced mathematics theory to solve problems in the field of traditional Chinese medicine, mainly the application of mathematical modeling and mathematical methods.. For example, the mathematical modeling of the internal laws of traditional Chinese medicine includes: syndrome s research, symptoms research, yin and yang five elements research, etc.; Mathematical modeling of traditional Chinese medicine includes: prescription research, pharmacological research of traditional Chinese medicine, diagnosis of traditional Chinese medicine, pharmacodynamic evaluation research, pharmacokinetics research, extraction studies, etc. Traditional Chinese medicine applications of mathematical methods, such as orthogonal design, multivariate statistical analysis (including: cluster analysis, logistic regression analysis, fuzzy mathematics), etc., where fuzzy mathematics has played a certain role in the study of Chinese medicine, making the quantification of Chinese medicine blurred concepts become possible, playing an important role in TCM syndrome differentiation theory, TCM clinical research, TCM and prescription research, tongue diagnosis and pulse diagnosis research, TCM expert diagnosis and treatment system, and evaluation of Chinese herbal medicine grade. The third is the development target layer, integrating mathematical theory with traditional Chinese medicine, enabling Chinese medicine to insert "mathematical wings", obtaining an accelerated mechanism for the development of traditional Chinese medicine, promoting the rapid development of Chinese medicine, and realizing the modernization of traditional Chinese medicine.

\section{TEACHING REFORM AND CONSTRUCTION OF NEW TALENT TRAINING MODE}

Under the guidance of the above value orientation, in the classroom teaching, we must not only pay attention to studying mathematics, but also to using mathematics. In the current stage of rapid development of information technology, computers are widely used. Teachers should pay attention to cultivating students' awareness and ability to use mathematical principles and methods to think and deal with problems. In the classroom, they should downplay the form, introduce mathematics thoughts, and emphasize the formation process of mathematics thinking methods and the actual background and application fields of abstract concepts; so that students can know that the purpose of learning is to use, and to learn in the teaching goal of "application-oriented, sufficient use”.

Carrying out teaching reform and paying attention to the improvement of teaching methods, we can adopt the rich- designed knowledge introduction method, the process-oriented heuristic teaching, the combination of professional characteristics and mathematical modeling method, and the penetration of mathematics history into the teaching method to achieve its value orientation.

\section{A. Rich-designed knowledge introduction method}

In the teaching of advanced mathematics, the introduction of a class has a great influence on the students' learning effect. Therefore, the methods introduced are different for different contents. The main methods include the introduction of interesting stories, the introduction of background knowledge, and the introduction of learning situations. , the introduction of practical problems, and the introduction of review old lessons, and so on.

\section{B. Focus on process heuristic teaching}

Process heuristics are also called heuristics that point to thinking processes and thinking methods. That is, according to the thinking methods required by students to learn knowledge and skills, the corresponding heuristic questions are designed according to the thinking process, and the students are inspired to think according to the problems involved, and gradually transition to the teaching methods that allow students to ask questions and self-inspire. This method regards students as the main body of learning, gives full play to the subjective role of students' learning, and mobilizes students' enthusiasm for learning. It is the ability of students to learn actively, actively explore, and passively accept knowledge as active learning, which can improve students' learning efficiency and enhance students' interest in learning.

\section{Combining professional characteristics with mathematical modeling}

Advanced mathematics is a theoretically strong subject, and most students feel boring. So at the level, therefore, on the basis of hierarchical and sub-professional teaching, the introduction of mathematical models to enhance the applicability of mathematics can arouse students' interest and curiosity. For example, for Chinese medicine majors, using functions, numerical quantification, fuzzy mathematics, and branch mathematics to study the basic theory of Chinese medicine (Traditional Chinese Medicine Yin Yang theory, Chinese medicine five elements theory), dialectical treatment, Chinese medicine efficacy evaluation, using mathematical dynamic models and multivariate dynamic models to study the interaction between acupuncture points and so on. The application of mathematical modeling in pharmacokinetics has been relatively mature. The mathematical model has played an important role in drug evaluation, new drug design, drug dosage form improvement, and clinical guidance for rational drug use.

\section{Mathematical history penetration method}

The British science historian Dampier once said: "Nothing is more attractive than the story of scientific development." In the history of mathematics, there are many people and things worth remembering. Their contribution to mathematics allows us to have a perceptual understanding of mathematics itself, so 
that mathematics is no longer a boring theoretical book. Putting the history of mathematics into the teaching of advanced mathematics properly, what present in front of the students are no longer a dry concept, theorem, and formula, but a living scene with sound and color, flesh and blood. Explaining mathematics knowledge in such a well-designed threedimensional context not only increases the context, stimulates interest in learning, but also expands the knowledge of students.

The core starting point of the new talent training model is to position the application value and importance of mathematics in the field of traditional Chinese medicine, and to integrate this position with the goal of training talents of Chinese medicine, which is reflected in the specific goal of talent cultivation, meanwhile this positioning and goals are shared between teachers and students, so that students have the goal to learn, understand what to learn, why to learn, how to learn; and the teachers have the goal of teaching, familiar with what to teach, why to teach, how to teach, then thoroughly Change the situation of "mathematics is useless" and greatly enhance students' interest in learning; At the same time, teachers should pay attention to the reform of the teaching process, introduce adaptive teaching methods, and construct a new set of talent training mode, as shown in Fig 1.

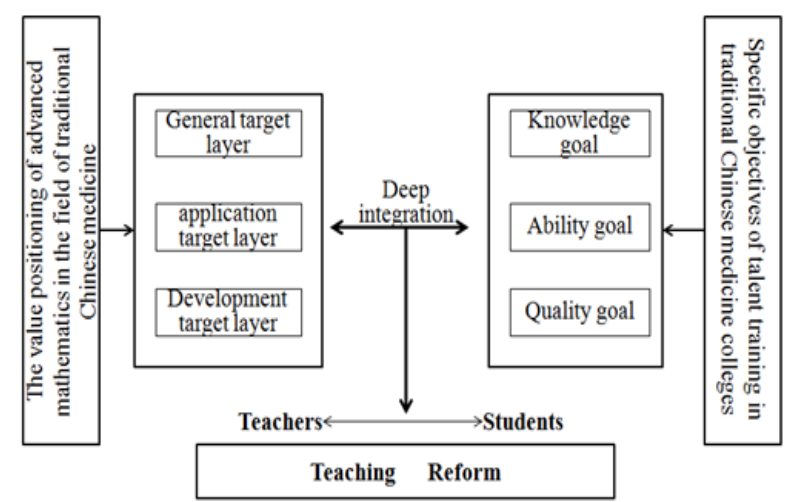

Fig. 1. The New Training Mode of Advanced Mathematics Talents in Traditional Chinese Medicine Colleges and Universities

\section{THE CONCLUSION, THE APPLICATION AND PROMOTION OF RESEARCH RESULTS}

By exploring the value orientation of advanced mathematics in the field of traditional Chinese medicine, and integrating this position with the goal of training Chinese medicine professionals, it will promote the reform of advanced mathematics teaching in Chinese medicine colleges, change the students' concept of " mathematics is useless ", and train students using mathematics thinking to understand, analyze and solve related problems in the field of traditional Chinese medicine. This is conducive to promoting the transformation of Chinese medicine research from qualitative to quantitative, from empirical science to experimental science, thereby promoting the efficient and rapid development of traditional Chinese medicine and realizing the modernization of traditional Chinese medicine.

\section{ACKNOWLEDGEMENT}

This work is supported by Shandong Education Science Planning Project, special subject of higher education subject teaching, Research on Advanced Mathematics Teaching Reform Based on the Perspective of Traditional Chinese Medicine Application. The author would like to acknowledge the referees for their valuable comments and suggestions which helped to improve the presentation of this paper.

\section{REFERENCE}

[1] Licui Gu. Discussion Form of Discussion Teaching Method in Higher Mathematics of Medicine [J]. Heilongjiang Medicine Journal,2014.03. In Chinese.

[2] Xiaohu Zhu. Recent application of fuzzy mathematics in the study of traditional Chinese medicine[J]. Journal of Emergency in Traditional Chinese Medicine,2013.08. In Chinese.

[3] Weiping Chen. Advanced Mathematics Curriculum and Teaching Reform Based on the Perspective of Mathematical Modeling[J]. New Curriculum Research,2016. In Chinese.

[4] Huiqin Tang. Application and Thinking of Mathematical Model in Traditional Chinese Medicine Research[J]. Chinese Traditional Patent Medicine,2013.04. In Chinese.

[5] Wang Yayun.Talking about the Problems and Countermeasures of Higher Mathematics Teaching in Traditional Chinese Medicine[J]. Technological Horizon,2012.02. In Chinese.

[6] Yan Yunliang.Medical higher mathematics[M]. 4th edition. Beijing: Science Press, 2012. 